Article

\title{
Propolis-Based Nanofiber Patches to Repair Corneal Microbial Keratitis
}

\author{
Songul Ulag 1,2, Elif Ilhan 1,3, Ramazan Demirhan ${ }^{1}$, Ali Sahin 4,5 ${ }^{\mathbb{D}}$, Betul Karademir Yilmaz ${ }^{4,5}$, Burak Aksu ${ }^{6} \mathbb{D}_{\text {, }}$ \\ Mustafa Sengor ${ }^{1,7}$, Denisa Ficai ${ }^{8,9}$, Aurel Mihail Titu 10,11(D), Anton Ficai ${ }^{8,9,11, *(D)}$ and Oguzhan Gunduz ${ }^{1,7, *(D)}$
}

1 Center for Nanotechnology \& Biomaterials Application and Research (NBUAM), Marmara University, 34722 Istanbul, Turkey; ulagitu1773@gmail.com (S.U.); eliffguven@gmail.com (E.I.); r.demirhan@outlook.com (R.D.); mustafasengor@gmail.com (M.S.)

2 Metallurgical and Materials Engineering, Institute of Pure and Applied Sciences, Marmara University, 34722 Istanbul, Turkey

3 Department of Bioengineering, Institute of Pure and Applied Sciences, Marmara University, 34722 Istanbul, Turkey

4 Department of Biochemistry, Faculty of Medicine, Marmara University, 34718 Istanbul, Turkey; alisahin@marmara.edu.tr (A.S.); btlkarademir@gmail.com (B.K.Y.)

5 Genetic and Metabolic Diseases Research and Investigation Center, Marmara University, 34722 Istanbul, Turkey

6 Department of Medical Microbiology, Marmara University School of Medicine, 34854 Istanbul, Turkey; drbaksu@gmail.com

7 Metallurgical and Materials Engineering Faculty of Technology, Marmara University, 34722 Istanbul, Turkey

8 Faculty of Applied Chemistry and Materials Science, University Politehnica of Bucharest, 060042 Bucharest, Romania; denisa.ficai@upb.ro

check for

updates

Citation: Ulag, S.; Ilhan, E.;

Demirhan, R.; Sahin, A.; Yilmaz, B.K.;

Aksu, B.; Sengor, M.; Ficai, D.; Titu,

A.M.; Ficai, A.; et al. Propolis-Based

Nanofiber Patches to Repair Corneal

Microbial Keratitis. Molecules 2021, 26,

2577. https://doi.org/10.3390/

molecules 26092577

Academic Editor: Heiko Lange

Received: 24 March 2021

Accepted: 26 April 2021

Published: 28 April 2021

Publisher's Note: MDPI stays neutral with regard to jurisdictional claims in published maps and institutional affiliations.

Copyright: (c) 2021 by the authors. Licensee MDPI, Basel, Switzerland. This article is an open access article distributed under the terms and conditions of the Creative Commons Attribution (CC BY) license (https:// creativecommons.org/licenses/by/ $4.0 /)$.
9 National Centre for Micro- and Nanomaterials, University Politehnica of Bucharest, 060042 Bucharest, Romania

10 Industrial Engineering and Management Department, Faculty of Engineering, Lucian Blaga University of Sibiu, 550025 Sibiu, Romania; mihail.titu@ulbsibiu.ro

11 Academy of Romanian Scientists, 050094 Bucharest, Romania

* Correspondence: anton.ficai@upb.ro (A.F.); ucemogu@ucl.ac.uk (O.G.)

Abstract: In this research, polyvinyl-alcohol (PVA)/gelatin (GEL)/propolis (Ps) biocompatible nanofiber patches were fabricated via electrospinning technique. The controlled release of Propolis, surface wettability behaviors, antimicrobial activities against the $S$. aureus and P. aeruginosa, and biocompatibility properties with the mesenchymal stem cells (MSCs) were investigated in detail. By adding $0.5,1$, and $3 \mathrm{wt} . \%$ GEL into the $13 \mathrm{wt} . \%$ PVA, the morphological and mechanical results suggested that 13 wt.\% PVA/0.5 wt.\% GEL patch can be an ideal matrix for 3 and 5 wt.\% propolis addition. Morphological results revealed that the diameters of the electrospun nanofiber patches were increased with GEL (from $290 \mathrm{~nm}$ to $400 \mathrm{~nm}$ ) and Ps addition and crosslinking process cause the formation of thicker nanofibers. The tensile strength and elongation at break enhancement were also determined for 13 wt.\% PVA/0.5 wt.\% GEL/3 wt.\% Ps patch. Propolis was released quickly in the first hour and arrived at a plateau. Cell culture and contact angle results confirmed that the 3 wt. $\%$ addition of propolis reinforced mesenchymal stem cell proliferation and wettability properties of the patches. The antimicrobial activity demonstrated that propolis loaded patches had antibacterial activity against the $S$. aureus, but for P. aeruginosa, more studies should be performed.

Keywords: corneal patch; electrospinning; microbial keratitis; nanofibers; propolis; P. aeruginosa; S. aureus

\section{Introduction}

The cornea is a protective, transparent, and outer covering of an eyeball. It's a tissue that acts as a structural barrier and protects the eye against infections, mechanical damage, and ultraviolet (UV) radiation. Two of its main functions are transmission and 
refraction of incident light beams and contribute to three-fourth of the total refractive power of the eye [1]. The cornea constructs have cellular and acellular elements. The cellular components are composed of epithelial cells, keratocytes, and endothelial cells. The acellular components consist of collagen and glycosaminoglycan. The cornea consists of five layers, the epithelium, Bowman's layer, stroma, Descemet's membrane, and endothelium, and, in humans, the central corneal thickness is about $550 \mu \mathrm{m}$, and the peripheral thickness is about $620 \mu \mathrm{m}$. The thickness is decreasing with age [2]. The cornea diseases are a significant cause of blindness worldwide, being the second, after the cataract, in overall importance. The cornea diseases include infections and inflammation that cause corneal scarring, which ultimately leads to functional blindness [3]. Nowadays, cataract is the cause of approximately $50 \%$ of all blindness worldwide, $15 \%$ due to trachoma, $10 \%$ due to uncorrected refractive error, $4 \%$ due to childhood corneal blindness, and $1 \%$ due to onchocerciasis. These five diseases are responsible for up to $80 \%$ of the world's blindness [4]. Trachoma is the second leading cause of corneal blindness after the cataract, mainly due to corneal scarring and vascularization. The World Health Organization (WHO) estimates that there are about 146 million people worldwide who have trachoma, and 10 million require surgery to prevent corneal blindness as a result of trachoma. Ocular trauma, corneal ulceration, and childhood corneal blind-ness are other causes of blindness [5]. Corneal ulceration, or microbial keratitis, is a familiar ocular infection that can be caused by fungi, bacteria, viruses, and parasites [6]. Pseudomonas species are the most common microbial strains that causes the contact lens-related bacterial ulcers [7] and the postlens tear surroundings may permit Pseudomonas to attach to the corneal epithelium [8,9]. Staphylococcus aureus (S. aureus) is another ordinary pathogen of the eye, which has the potential to infect external tissues such as the conjunctiva, tear duct, and cornea. This bacterium allows various toxins and enzymes that can damage tissues and organs, and this damage can cause blindness in the framework of ocular diseases [10]. To treat bacterial damages, it is still not found in precise clinical treatments. Hence, more studies are needed to know the special organism and a therapeutic plan should be formed related to clinical reaction [11].

Electrospinning is one of the best production techniques used in tissue engineering applications to produce tissue scaffolds using various polymers [12]. Electrospinning is used as a method that enables the production of biomimetic scaffolds consisting of a large network of interconnected fibers and pores. The high porosity allows efficient nutrient and metabolic waste exchange between the scaffolds and their surroundings. It also provides a high surface area for the continuous delivery of biochemicals to the seeded cells [13-15]. Many different natural and synthetic polymers are widely preferred in many tissue engineering studies, drug delivery systems, and regenerative medicine applications due to their unique properties such as biocompatibility, non-toxicity, and biodegradability $[16,17]$. PVA in the form of the hydrogel are generally used in tissue engineering, such as arterial phantom, corneal implants, and cartilages [18,19]. It is a hydrophilic, biocompatible, a biodegradable polymer, and it supports the improvement of oxygen permeability [20]. Gelatin is a biocompatible fibrous protein and has moderate antibacterial activity [21]. Its fibrous structure can mimic the collagen fibril structure of the cornea stroma. In Pal et al.'s study, they also fabricated the PVA/Gel film for an artificial skin material [22]. In another study performed by Huang et al., they investigated the comparison of randomly oriented and aligned PVA/Gel nanofibers and reported that cells on PVA-gelatin aligned fibers stretch out extensively [23]. Jain et al. loaded ciprofloxacin in PVA/Gel blends by solution casting method for treatment of corneal ulcers, bacterial keratitis, and other corneal infectious. They proved that PVA/gelatin blends are favorable for controlled release of antibiotic in the eye as compared to the traditional eye drops. [24]. To provide antimicrobial activity against the S. aureus and P. aeruginosa, propolis was chosen due to its phenolic compounds, which provide antibacterial and antioxidant activity $[25,26]$. In studies conducted in the literature, with separation techniques such as mass spectroscopy (MS), nuclear magnetic resonance (NMR), chromatography and mass 
spectroscopy (GC-MS), compounds such as flavonoids, terpenes, phenolics and their esters, sugars, hydrocarbons, and mineral elements have been identified in propolis content $[27,28]$. The biological activities of propolis are attributed to a variety of major chemical constituents including phenolic acids, phenolic acid esters, flavonoids, and terpenoids such as CAPE, caffeic acid, chrysin, and quercetin, apigenin, kaempferol, pinobanksin 5- ethyl ether, pinocembrin [29]. The main parts of the propolis compounds are flavonoids, which have the $25 \%$ ratio [30]. These compounds acquire their antioxidant properties through the lipid peroxidation mechanism [31]. Based on these significant properties, it is widely used in wound healing applications [32].

In this study, PVA, GEL, and propolis which materials are widely used in biomedical applications were used to treatment of corneal keratitis.

\section{Materials and Method}

\subsection{Materials}

Polyvinyl alcohol (PVA, MW = 89,000-98,000) was provided from Sigma Aldrich (Saint Louis, MO, USA), and propolis extract was supplied from SBS (Scientific Bio Solutions) Company, Istanbul, Turkey. Glutaraldehyde (25\% solution in water) was provided from Merck KGaA, Darmstadt, Germany.

\subsection{Fabrication and Characterization of the Electrospinning Solutions}

Firstly, 13 wt.\% PVA was put into a beaker containing $20 \mathrm{~mL}$ of distilled water and dissolved at $300 \mathrm{rpm}, 80^{\circ} \mathrm{C}$ on magnetic stirrer. After $13 \%$ PVA solution dissolved, $0.5,1$, and $3 \mathrm{wt} . \%$ GEL were put into this solution. To diminish the surface tension, 3\% Tween 80 (Merck KGaA, 64271, Germany) was put into the solutions and stirred for $15 \mathrm{~min}$. After the morphological and mechanical characterizations of $13 \mathrm{wt} . \% \mathrm{PVA} /(0.5,1,3) \mathrm{wt} . \%$ GEL patches, it was obtained that $13 \mathrm{wt.PVA} / 0.5 \mathrm{wt} . \%$ GEL was better than other concentrations. Therefore, propolis was added directly into $13 \mathrm{wt} . \%$ PVA $/ 0.5 \mathrm{wt} . \%$ GEL patch to fabricate the propolis added biofunctional patches.

After the preparation of the solutions, these were used to fabricate nanofiber corneal patches via electrospinning. During the electrospinning process; flow rate, voltage, and distance between the collector and needle were optimized. In the electrospinning set-up, a syringe pump (NE-300, New Era Pump Inc., Toledo, OH, USA), a single brass needle (1.63 $\mathrm{mm}$ of diameter), and a power supply with high voltage were used with a laboratoryscale electrospinning machine (Inovenso, Istanbul, Turkey). Firstly, polymer solutions were taken into the $10 \mathrm{~mL}$ plastic syringes. Then, a high voltage was applied to obtain the Taylor cone. The electrospinning parameters of this study were $24-26 \mathrm{kV}, 2-3 \mathrm{~mL} / \mathrm{h}$ flow rate, $120 \mathrm{~mm}$ working distance. As a final stage, $0.25 \%$ Glutaraldehyde (GA) was used as a vapor to crosslink the nanofiber patches in the desiccator for $2 \mathrm{~h}$ at $40{ }^{\circ} \mathrm{C}$. Then they were dried at room temperature overnight.

\subsection{Characterization of the Fabricated Corneal Patches}

To observe the physicochemical characterizations of the corneal patches, Jasco FT/IR4700 model machine was performed at room temperature over the range of $4000-400 \mathrm{~cm}^{-1}$ in the transmission mode with $4 \mathrm{~cm}^{-1}$ resolution (32 scans).

Scanning electron microscopy (SEM, EVO LS 10, ZEISS) was utilized to investigate the morphological structures of the fabricated corneal patches. Before the analysis, patches were coated with gold-palladium for $120 \mathrm{~s}$ with a Quorum SC7620 sputter coater. During the analysis, $10 \mathrm{kV}$ accelerating voltage was applied. Image software (Olympus AnalySIS, USA) was employed to measure the average fiber diameter of the SEM images.

To determine the thermal properties of the fabricated corneal patches, differential scanning calorimetry (DSC, Shimadzu, Japan) was employed with a temperature range of $25-300{ }^{\circ} \mathrm{C}$. The heating rate kept constant at $10^{\circ} \mathrm{C} / \mathrm{min}$ for all patches.

In the antimicrobial test, the corneal patches were tested against $S$. aureus and $P$. aeruginosa to observe the antimicrobial activity of the corneal patches. Before the test, $S$. 
aureus and $P$. aeruginosa were cultured overnight to acquire bacterial suspensions. An automated plate inoculator was utilized to inoculate the bacterial suspensions on MuellerHinton agar plates. The fabricated corneal patches were cut to have $5 \mathrm{~mm}$ in diameter. The sterilization process was performed with UV light $(254 \mathrm{~nm})$ for an hour. As a control group, $2 \mu \mathrm{g}$ ampicillin was used, and then the disks were cultured at $37^{\circ} \mathrm{C}$ for $18 \mathrm{~h}$. After the antimicrobial test finished, the growth inhibition zones were measured.

The uniaxial tensile testing device (Shimadzu Corporation, EZ-LX, Kyoto, Japan) was also used to determine the mechanical behaviors of the patches. Before the measurement, each patch was cut with a $5 \mathrm{~cm}$ in length and $1 \mathrm{~cm}$ in width mold. The thickness values of each nanofiber patches were measured with a digital micrometer (Mitutoyo, Santa Ana, CA, USA). The test speed was adjusted to $5 \mathrm{~mm} / \mathrm{min}$ and $5 \mathrm{kN}$ load cell was applied during the test for all patches.

In the drug release test, the first step is the determination of the linear calibration curve. For this purpose, 5 different Ps concentrations were prepared $(2,4,6,8$, and $10 \mu \mathrm{g} / \mathrm{mL})$. The drug release analysis was carried out to examine the release behaviors of 3 and $5 \%$ Ps into the $13 \%$ PVA $/ 0.5 \%$ GEL matrix. Firstly, $5 \mathrm{mg}$ of Ps loaded patches were kept in $1 \mathrm{~mL}$ PBS ( $\mathrm{pH} 7.4$ ) for $6 \mathrm{~h}$ at $37^{\circ} \mathrm{C}$ to investigate their release behavior. At predetermined times $(0,0.25,0.5,1,2,3,4$, and $6 \mathrm{~h}), 1 \mathrm{~mL}$ PBS was taken out from each sample and replaced with $1 \mathrm{~mL}$ of fresh PBS. The releasing profile of the Ps was determined at $241 \mathrm{~nm}$ by using UV spectroscopy (Shimadzu UV-3600, Kyoto, Japan) and the behaviors were in agreement with the first-order model.

Human adipose-derived mesenchymal stem cells (hADMSCs) were bought from the American Type Culture Collection (ATCC-PCS-500-011). Dulbecco's Eagle Medium (DMEM) supplemented with 10\% fetal bovine serum (FBS), 1\% Penicillin/Streptomycin was incubated with cells at $37{ }^{\circ} \mathrm{C}$, in presence of $5 \% \mathrm{CO}_{2}$ atmosphere. All corneal patches were sterilized with UV in the 24 well plates before the analysis. To observe the cell viability on corneal patches, patches were incubated with DMEM supported with $10 \%$ fetal bovine serum, $1 \%$ Penicillin/Streptomycin $2 \times 10^{4}$ cells per well. The medium $(500 \mu \mathrm{L})$ was changed daily. In the MTT protocol; MTT reagent (Sigma) was used to measure the cell viability on the patches, and by using its solution in PBS $(5 \mathrm{mg} / \mathrm{mL}) 100 \mu \mathrm{L}$ was taken from this stock and patches incubated with cells and DMEM for $3 \mathrm{~h}$ at $37^{\circ} \mathrm{C}, 5 \% \mathrm{CO}_{2}$ for 1,3 , and 7 days. DMEM was removed from the plate, and formazan crystals were dissolved in $500 \mu \mathrm{L}$ DMSO and detected at $570 \mathrm{~nm}$.

Contact angle measurements were performed to determine the wettability of the corneal patches with the sessile drop method (TGX tensiometer) at room temperature. $3 \mu \mathrm{L}$ distilled water droplets were dropped on the surface of the nanofiber patches. CCD camera connected to the equipment was used to record the images after $2 \mathrm{~s}$ evaluation. The water contact angle values were automatically calculated by the software.

\section{Results and Discussions}

\subsection{Morphological Properties of the Corneal Patches}

Figure 1 represented the SEM images of the non-crosslinked 13 wt.\% PVA and 13 wt.\% PVA/(0.5, 1, and 3)wt.\% GEL nanofiber patches. The images indicated that all nanofiber patches had homogeneous, continuous, and bead free morphologies. These uniform and smooth morphologies created a porous network to provide diffusion of nutrients and oxygen to the attached cells [33]. The diameters of the electrospun fibers ranged from $293 \mathrm{~nm}$ to $401 \mathrm{~nm}$. It was observed that at the constant voltage $(26 \mathrm{kV})$ and flow rate $(2 \mathrm{~mL} / \mathrm{h})$ values, by the addition of GEL into the $13 \%$ PVA, the diameters of the nanofiber patches increased. However, it could be seen that with an increase of GEL concentration, uniform fiber structure without any beads was still preserved. 

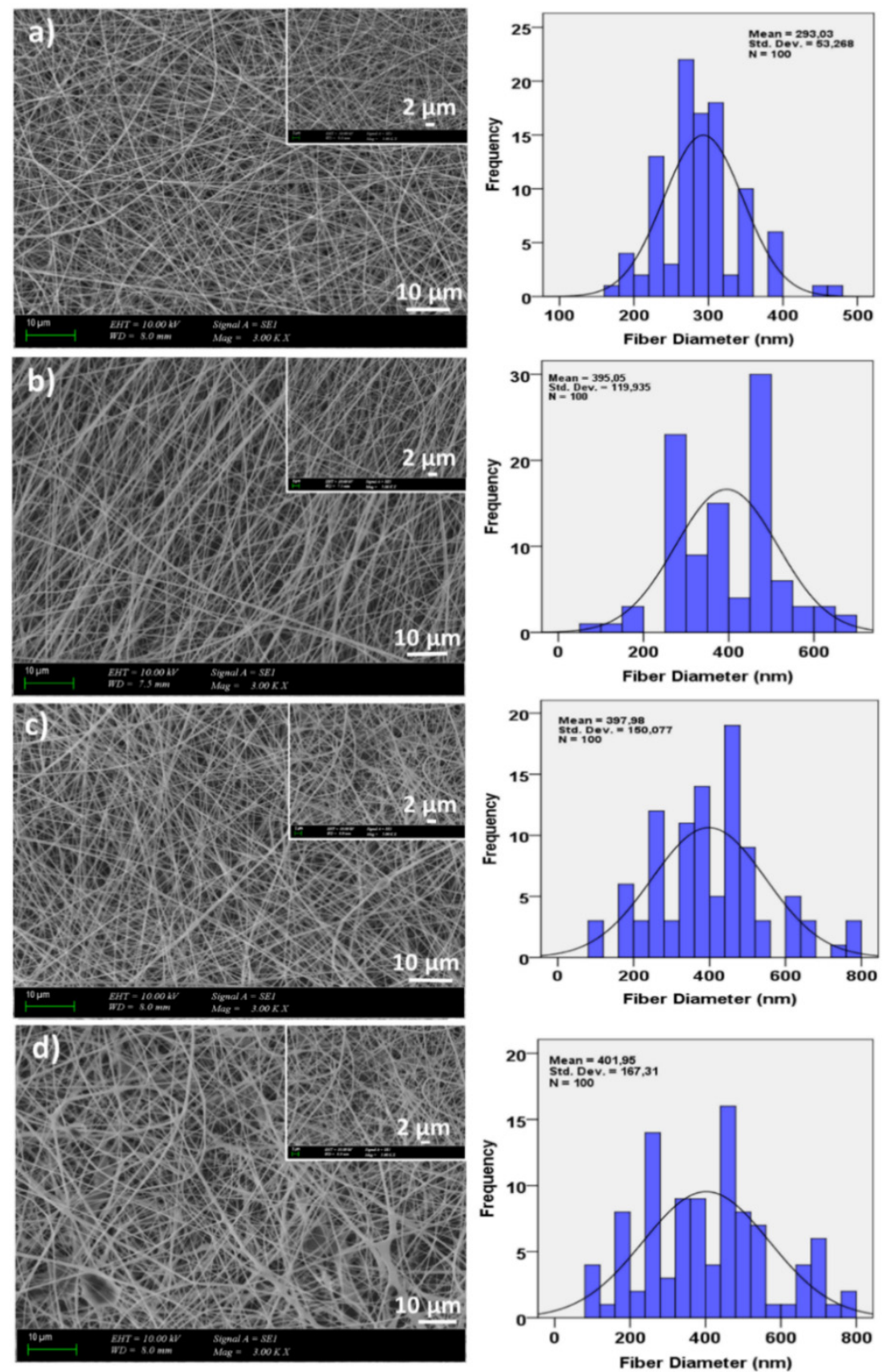

Figure 1. SEM images of the non-crosslinked 13\% PVA (a), 13\% PVA/0.5\% GEL (b), 13\% PVA/1\% GEL (c), 13\% PVA/3\% GEL (d).

After adding three different proportions of gel into the PVA polymer, it was observed that the gel preserved the uniform structure of the PVA polymer in all proportions. Still, it was also noted that the nanofiber diameter increased. Additionally, the tensile test showed that by adding GEL into PVA polymer solution, the tensile strength values of the patches decreased. Based on the mechanical and morphological results, 13wt.\% PVA/0.5 wt.\% GEL was deemed suitable for adding propolis.

PVA and GEL are water-soluble polymers, so they should be crosslinked for providing water-resistant (stable) biomedical materials [34]. Figure 2 revealed the GA-crosslinked 13 wt.\% PVA, 13 wt.\% PVA/0.5 wt.\% GEL, and 13 wt.\% PVA/0.5 wt.\% GEL/(3 and 5)wt.\% Ps nanofiber patches. It was seen in Figure $2 \mathrm{a}-\mathrm{d}$ that the crosslinking process did not affect the uniform and beadless structures of the $13 \mathrm{wt} . \%$ PVA and $13 \mathrm{wt} . \%$ PVA $/ 0.5 \mathrm{wt} . \%$ GEL patches. Figure 2e-f showed the smooth and beadless structures of the 13wt.\% PVA/ 0.5 wt. $\%$ GEL $/ 3$ wt.\% Ps nanofiber patches. It can be easily seen that the crosslinking process causes the thicker diameter of the nanofibers. Moreover, the SEM images of 
the 13 wt. $\%$ PVA/ 0.5 wt.\% GEL/5 wt.\% Ps also had thicker diameters compared to the non-crosslinked 13 wt. $\%$ PVA and 13 wt.\% PVA $/(0.5,1$, and 3)wt. \% GEL nanofiber patches.
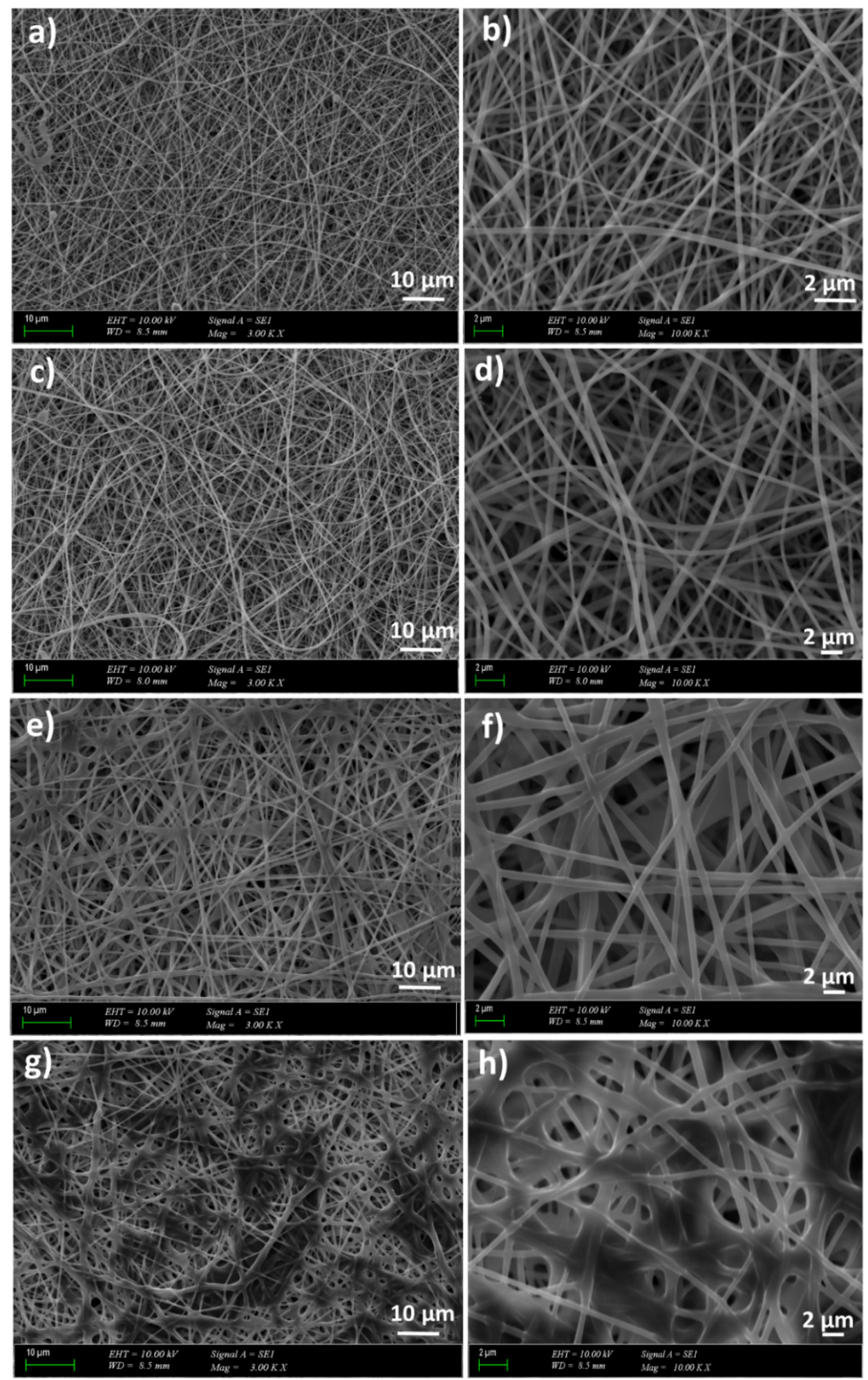

Figure 2. SEM images of the GA-crosslinked 13\% PVA (a,b), 13\% PVA/0.5\% GEL (c,d), 13\% PVA/0.5\% GEL $/ 3 \%$ Ps (e,f), $13 \%$ PVA $/ 0.5 \%$ GEL $/ 5 \%$ Ps $(\mathbf{g}, \mathbf{h})$.

\subsection{FTIR Analysis}

The FTIR spectra of GA crosslinked 13 wt.\% PVA, 13 wt.\% PVA/ $(0.5,1,3)$ wt. $\%$ GEL, and $13 \%$ PVA $/(0.5,1,3) \%$ GEL $/(3$ and 5$) \%$ Ps patches were shown in Figure 3A,B. In 
Figure 3A(a), the $13 \%$ PVA had main characteristic peaks at $\sim 3268.75 \mathrm{~cm}^{-1}$ (O-H group, N-H amino group), $\sim 2910 \mathrm{~cm}^{-1}$ (C-H stretch vibration), $\sim 1646.91 \mathrm{~cm}^{-1}, \sim 1417.42 \mathrm{~cm}^{-1}$ (C-O), $\sim 1326.79 \mathrm{~cm}^{-1}$ (C-H bending), $\sim 1261.22 \mathrm{~cm}^{-1}$ (C=O vibration), $\sim 1085.73 \mathrm{~cm}^{-1}$ (C-O group), $\sim 917.95 \mathrm{~cm}^{-1}$ (C-C stretching), and $\sim 821.53 \mathrm{~cm}^{-1}$ (C-O stretching) [24,25]. Figure $3 \mathrm{~A}(\mathrm{~b})$ represented the FTIR spectrums of the neat GEL which had characteristic peaks at $\sim 3277 \mathrm{~cm}^{-1}, \sim 2933 \mathrm{~cm}^{-1}, \sim 1626 \mathrm{~cm}^{-1}, \sim 1525 \mathrm{~cm}^{-1}, \sim 1442 \mathrm{~cm}^{-1}, \sim 1333 \mathrm{~cm}^{-1}$, $\sim 1234 \mathrm{~cm}^{-1}, \sim 1076 \mathrm{~cm}^{-1}, \sim 1027 \mathrm{~cm}^{-1}$, and $\sim 472 \mathrm{~cm}^{-1}$. The absorption peaks at $1626 \mathrm{~cm}^{-1}$, $1525 \mathrm{~cm}^{-1}$, and $1234 \mathrm{~cm}^{-1}$ represented the $v_{\mathrm{C}}=\mathrm{O}$ and $v_{\mathrm{CN}}$ stretching vibration of groups (amide carbonyl) in Amide I, to $\delta_{\mathrm{NH}}$ and $v_{\mathrm{CN}}$ vibration of groups in Amide II, and to $v_{\mathrm{CN}}$ and $\delta_{\mathrm{NH}}$ vibrations in the Amide III band [35]. Propolis extract had main absorption peaks at $3343 \mathrm{~cm}^{-1}, 2973 \mathrm{~cm}^{-1}, 2927 \mathrm{~cm}^{-1}, 1637 \mathrm{~cm}^{-1}, 1513 \mathrm{~cm}^{-1}, 1450 \mathrm{~cm}^{-1}$, $1376 \mathrm{~cm}^{-1}, 1270 \mathrm{~cm}^{-1}, 1164 \mathrm{~cm}^{-1}, 1085 \mathrm{~cm}^{-1}, 1043 \mathrm{~cm}^{-1}$, and $877 \mathrm{~cm}^{-1}$ (Figure 3A(c)) [36]. In Figure $3 \mathrm{~A}(\mathrm{~d})$, the FTIR spectrum of the $13 \%$ PVA $/ 0.5 \%$ GEL had nearly same spectrum with $13 \%$ PVA except the peak $1261 \mathrm{~cm}^{-1}$ which observed in FTIR spectrum of the $13 \%$ PVA. Additionally, the peak observed at $3270 \mathrm{~cm}^{-1}$ shifted to $3278 \mathrm{~cm}^{-1}$ with the $0.5 \%$ GEL addition. Figure 3A(e) represented the absorbance spectrum of the $13 \%$ PVA/ $0.5 \%$ GEL $/ 3 \%$ Ps. In this spectrum, propolis addition affected the absorbance spectrum of the 13\% PVA $/ 0.5 \%$ GEL patch in same points which peaks observed at $1731 \mathrm{~cm}^{-1}$, $1637 \mathrm{~cm}^{-1}, 1373 \mathrm{~cm}^{-1}, 1085 \mathrm{~cm}^{-1}$, and $1024 \mathrm{~cm}^{-1}$. In addition, by adding $5 \%$ Ps into the $13 \%$ PVA $/ 0.5 \%$ GEL the peaks observed at $1710 \mathrm{~cm}^{-1}, 1635 \mathrm{~cm}^{-1}$, and $1083 \mathrm{~cm}^{-1}$ were due to the PS addition, especially the peak detected at $1513 \mathrm{~cm}^{-1}$ (Figure $3 \mathrm{~A}(\mathrm{f})$ ).

\subsection{Thermal Properties of the Corneal Patches}

DSC analysis was performed to assess the thermal behavior of the $13 \%$ PVA, $13 \%$ PVA $/ 0.5 \%$ GEL, and 13\% PVA/0.5\% GEL/ (3 and 5)\% Ps nanofiber patches and to examine the miscibility of the blends [34]. Figure 3C,D shown the DSC curves of the pristine PVA, GEL, Ps, and 13\% PVA, 13\% PVA/0.5\% GEL blends at various propolis amounts fabricated by electrospinning. One peak observed at $228^{\circ} \mathrm{C}$ in the DSC curve of the pristine PVA and $13 \%$ PVA nanofiber patch is attributed to the melting point of PVA [34]. The peak observed at $232.2{ }^{\circ} \mathrm{C}$ represented the thermal degradation peak for pristine GEL [37]. Another peak detected at $89.44{ }^{\circ} \mathrm{C}$ showed the melting temperature of the pure GEL [38]. When the curve of propolis was examined, two important peaks were observed one is detected at $90.97^{\circ} \mathrm{C}$ which represented the water volatilization. Another peak observed at $123.6^{\circ} \mathrm{C}$ belonged to the fusion processes of low molecular weight compounds [39]. By adding $0.5 \%$ GEL into the $13 \%$ PVA, the melting point of the PVA did not change. However, with the addition of $3 \%$ Ps and 5\% Ps into the 13\% PVA/0.5\% GEL, the melting point decreased to $198{ }^{\circ} \mathrm{C}$ and $196^{\circ} \mathrm{C}$, respectively. A peak in the range of $50-60{ }^{\circ} \mathrm{C}$ may be due to the glass transition temperature of the PVA [40]. When 0.5\% GEL was added into the $13 \%$ PVA, the glass transition point decreases. Moreover, by adding Ps into the $13 \%$ PVA $/ 0.5 \%$ GEL, the glass transition temperature also reduced again. Miscible blends generally have a single glass transition and melting points in the mixture [41]. The DSC curve obtained in this study also had a single glass transition and melting points, which showed the excellent miscibility of PVA/GEL and PVA/GEL/Ps blends [42]. 

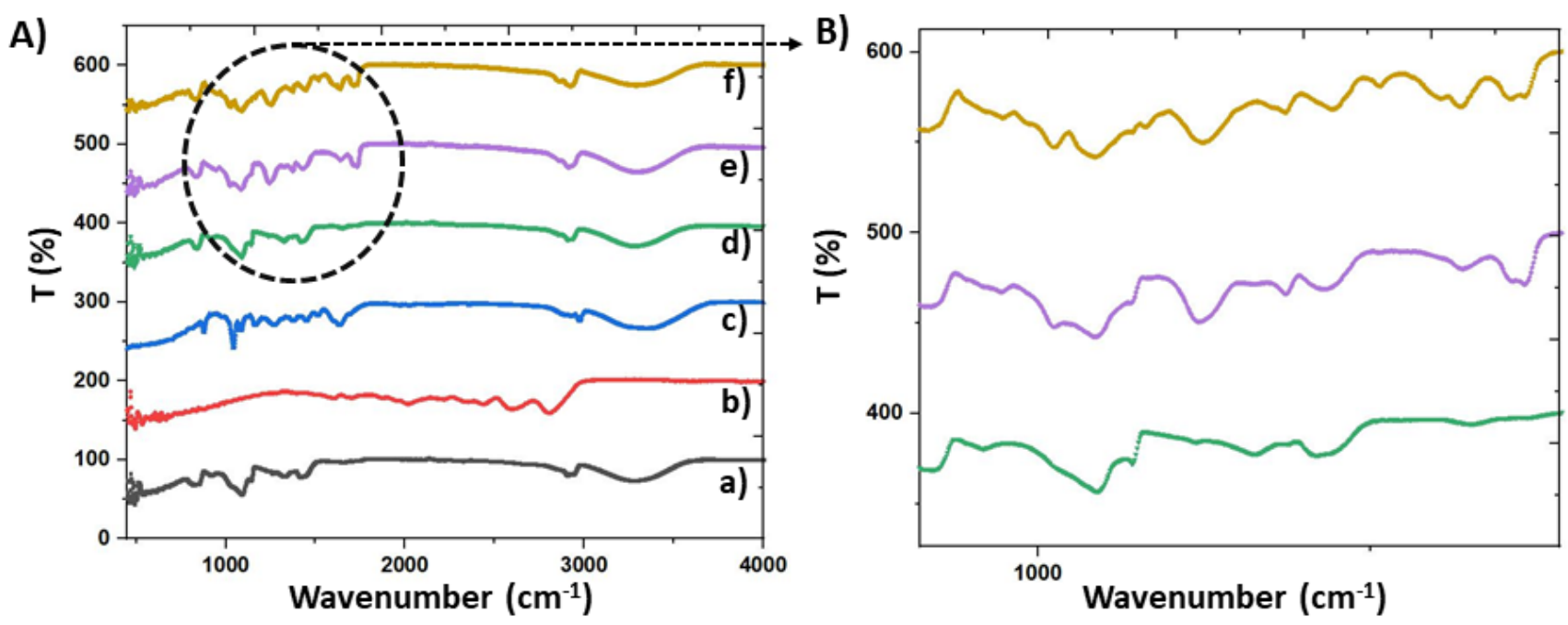

C)
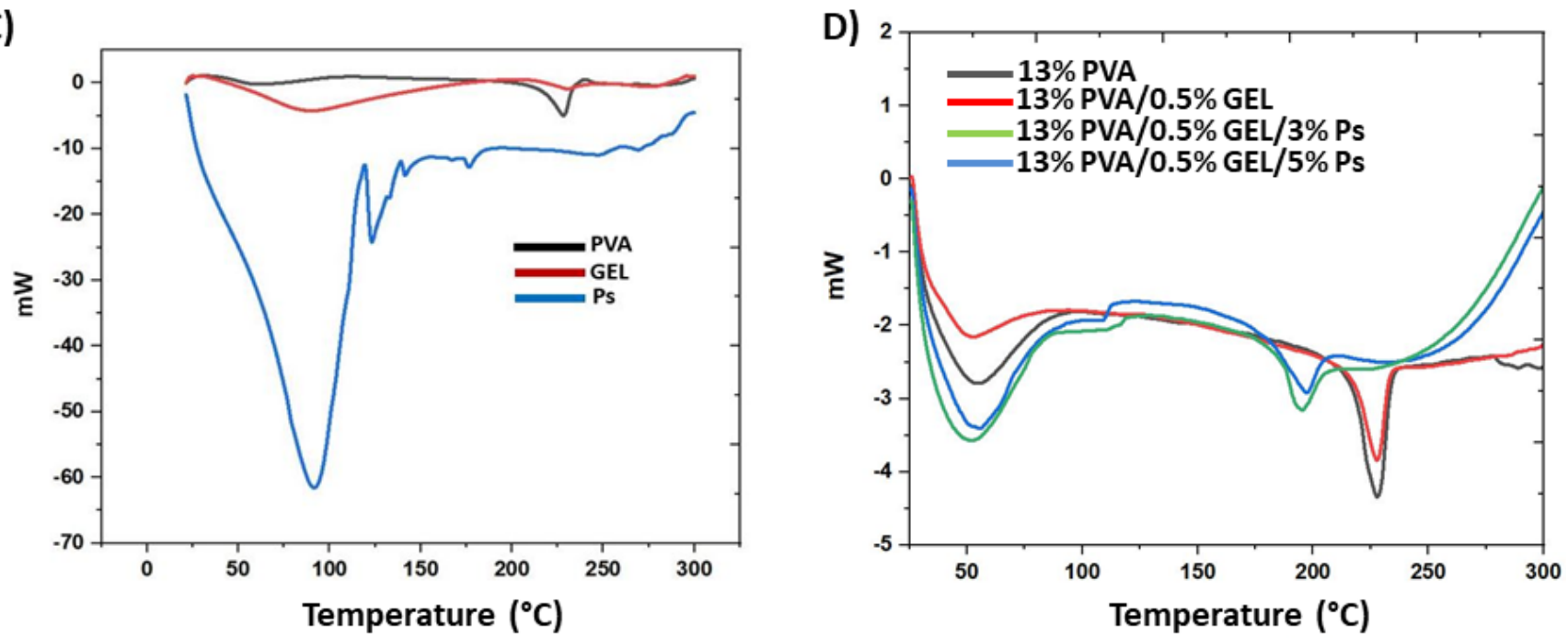

Figure 3. The labels (A,B) represented the FTIR spectrums: 13\% PVA (a), pure GEL (b) and Propolis (c), 13\% PVA/0.5\% GEL (d), 13\% PVA $/ 0.5 \%$ GEL/3\% Ps (e), 13\% PVA/0.5\% GEL/5\% Ps (f). (C,D) showed the DSC curves of the pristine PVA, GEL, Ps and prepared corneal patches.

\subsection{Antimicrobial Activity of the Fabricated Corneal Patches Against the S. aureus and P. aeruginosa}

Figure $4 \mathrm{~A}$ showed the antimicrobial activity of both control and propolis-based nanofiber patches against $S$. aeurous and P. aeruginosa. The results revealed that propolis added patches had antibacterial activity against the $S$. aureus with $7 \mathrm{~mm}$ inhibition zone. The 13\% PVA and 13\% PVA / $0.5 \%$ GEL patches were used as a control group in this test. Figure $4 \mathrm{~B}$ showed the antibacterial activity results of $13 \%$ PVA $/ 0.5 \%$ GEL $/ 3 \%$ Ps and $13 \%$ PVA $/ 0.5 \%$ GEL $/ 5 \%$ Ps nanofiber patches. According to the results, it was observed that propolis extract did not show any antibacterial activity against the P. aeruginosa. These results reported that propolis is a good extract for corneal keratitis, but further studies are required. There were performed some studies in the literature about the antibacterial activity of Ps against the S. aureus. In Arıkan et al.'s [43] work, propolis added patches showed antibacterial activity against $S$. aureus but did not show antibacterial activity against A. Baumanni and P. aeruginosa. In another study, Silici et al. [44] displayed important antibacterial activity against $S$. aureus but did not have antibacterial activity against $E$. coli and $P$. aeruginosa. In Aranc1 et al.'s [45] work, 3D-printed propolis added alginate scaffolds were fabricated to form wound dressing patches. 

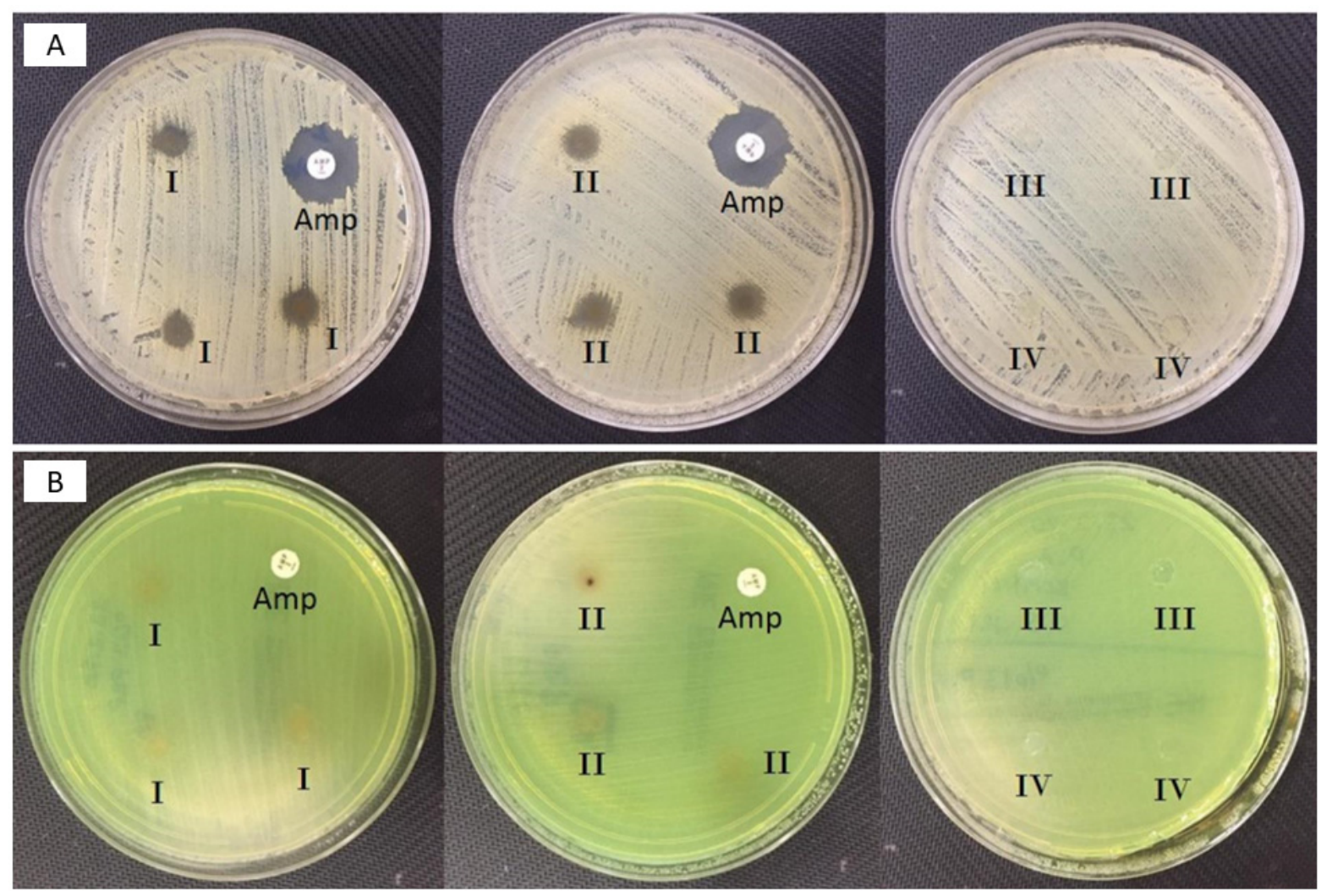

Figure 4. Staphylococcus aureus ATCC 29,213 tested by disk diffusion (A); I: 3\% propolis containing disk, II: 5\% propolis containing disk, III: 13\% PVA containing disk, IV: 0.5\% gel containing disk. Pseudomonas aeruginosa ATCC 27,853 tested by disk diffusion (B); I: 3\% propolis containing disk, II: 5\% propolis containing disk, III: 13\% PVA containing disk, IV: $0.5 \%$ gel containing disk.

\subsection{Mechanical Properties of the Corneal Patches}

The mechanical strength of ocular transplants is a prominent concern to resist the damage and sustained strength for determining insert performance [24]. The stress-strain behaviors of the electrospun corneal patches were given in Figure 5A-C. The tensile stress values of the $13 \% \mathrm{PVA} /(0.5,1$, and 3$) \%$ GEL decreased as the concentration of GEL increased. The elongation at break percentage of the 13\% PVA increased with $0.5 \%$ GEL addition from $13.86 \%$ to $36.32 \%$. However, by adding $1 \%$ and $3 \%$ GEL into the $13 \%$ PVA matrix, the elongation at break percentages decreased sharply. Therefore, the amount of $0.5 \%$ GEL was determined as the ratio to add propolis, and it was obtained that with the addition of 3\% Ps into the 13\% PVA/0.5\% GEL, the tensile stress values increased again from $3.75 \mathrm{MPa}$ to $8.12 \mathrm{MPa}$, propolis acting as a reinforcing agent. The adhesive qualities of propolis can be useful to increase the tensile stress values of PVA/GEL fibers [46]. On the other hand, elongation at break value (27.69\%) was lower than the value of $13 \%$ PVA $/ 0.5 \%$ GEL (36 and 32\%), but still higher than other GEL concentrations. By adding $5 \%$ Ps into the $13 \%$ PVA $/ 0.5 \%$ GEL, the tensile stress and elongation at break values decreased again. This can be explained due to the existence of propolis particles, which can prevent the precise orientation of polymer molecules and along with the heterogeneous structure cause a decrease in tensile strength values. If all patches are compared between each other, it can be said that $13 \%$ PVA, $13 \%$ PVA $/ 0.5 \%$ GEL, and $13 \%$ PVA $/ 0.5 \%$ GEL $/ 3 \%$ Ps had acceptable strength values for cornea tissue regeneration (3-5 MPa) [47]. The Young modulus of the nanofiber patches was calculated using the linear region of the stress/strain curve (Figure 5B). The results were revealed in Figure 5D with a column graph. According to the results, the same trend was observed between the patches like the tensile strength values of the patches. By adding $0.5,1$, and 3\% GEL into the $13 \%$ PVA, the elastic modulus values of the patches decreased slightly. How- 
ever, with the addition of 3\% Ps into the $13 \%$ PVA $/ 0.5 \%$ GEL, the elastic modulus of the nanofiber patches increased again from 1.85 $\mathrm{MPa}$ to $4.28 \mathrm{MPa}$. The elastic modulus of the $13 \%$ PVA $/ 0.5 \%$ GEL/5\% Ps was found as $2.57 \mathrm{MPa}$ and proved that $5 \%$ Ps ratio was too high to form mechanically corneal strength patches.
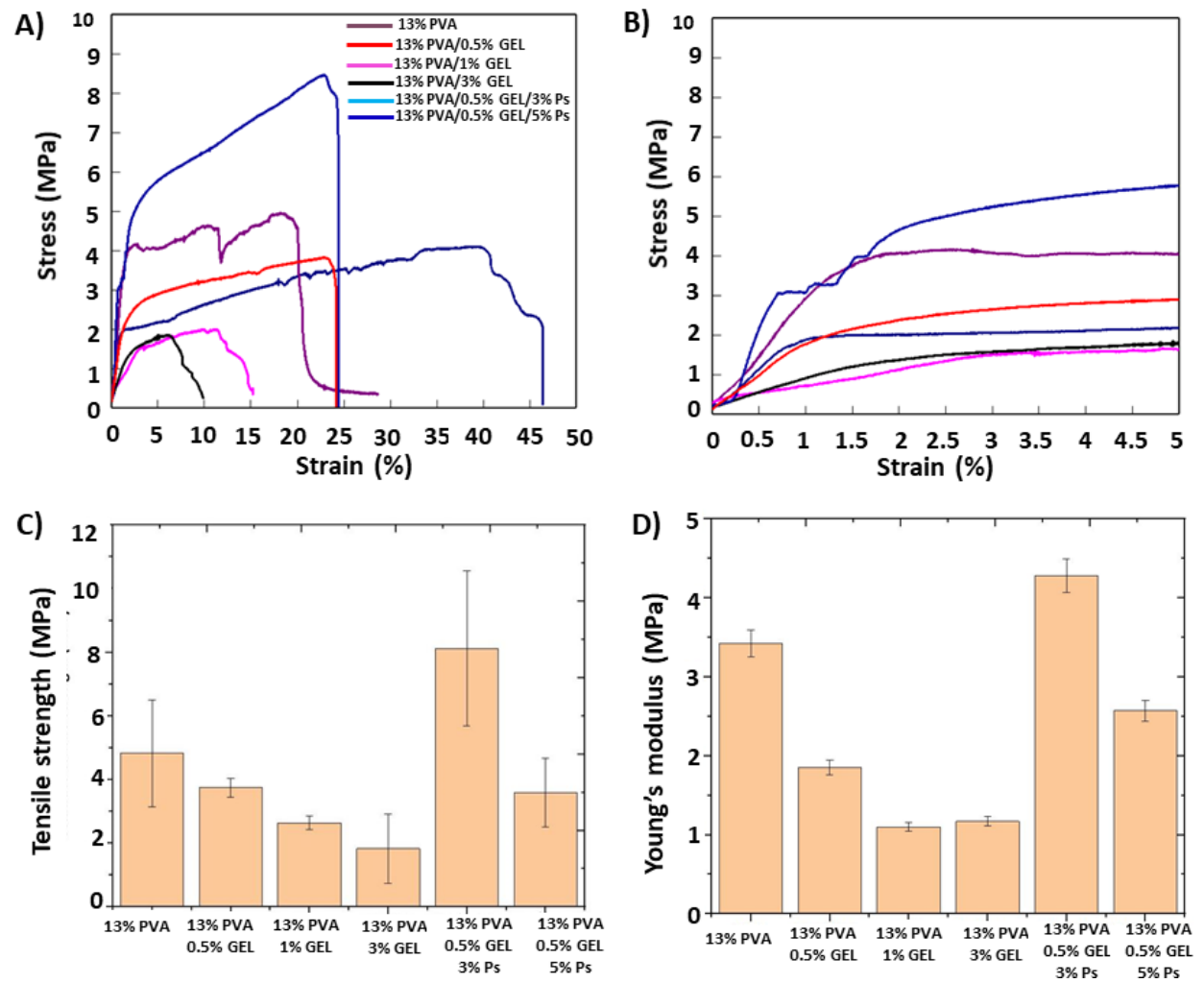

Figure 5. The typical stress/strain curve of the all-nanofiber patches using mean values of three measurements from each other (A,B), tensile strength (C), and calculated Young's modulus values (D) using the linear region of stress strain curve (B).

\subsection{Drug Release Profiles of Propolis}

In vitro, drug release analyzes of propolis-loaded nanofiber patches were performed. Firstly, for the quantitative determination of drug release (Figure 6a), a linear standard calibration curve was constructed from propolis absorption values $\left(R^{2}=0.9984\right)$ obtained and UV spectra (Figure 6b) obtained in the concentration range of propolis from 2 to $10 \mu \mathrm{g} / \mathrm{mL}$. Propolis released was detected by UV $241 \mathrm{~nm}$ absorbance. In order to mimic the physiological conditions of living organisms, the release profiles of propolis loaded nanofibers were analyzed at $37^{\circ} \mathrm{C}$ and $\mathrm{pH} 7.4$ in PBS. In vitro release studies were performed for $6 \mathrm{~h}$ to evaluate the release kinetics of propolis loaded nanofibers. As shown in Figure $6 c$, although the release rates were different at the two various propolis concentrations, both propolis loaded nanofibers showed burst drug release within the first $1 \mathrm{~h}$. This was primarily attributed to the high water solubility of PVA and Gel. Propolis release rates reached $82 \%$ and $71.14 \%$ in the first $1 \mathrm{~h}$ for $3 \%$ and $5 \%$, respectively. The drug release of nanofibers loaded with $3 \%$ propolis reached $100 \%$ at the end of approximately $3 \mathrm{~h}$, while the release of approximately the entire nanofiber loaded with 5\% propolis occurred at the end of the 5 th $\mathrm{h}$. According to the result obtained here, it is seen that the length of time of drug release is directly proportional to the amount of propolis loaded. Propolis release analysis from PVA hydrogels was performed in the study conducted by Oliveira et al. In the release analysis that lasted for 4 days in total, and it was reported that propolis exhibited a burst release profile on the 1st day and no prolonged release was observed. If the propolis concentration increased from $8 \%$ to $52 \%$, the release time increased as the amount of propolis increased [25]. In different research in the literature, the rapid release 
profile of propolis was observed at the beginning of the experiment. However, the in vitro release was made more controlled by increasing the propolis concentration [34]. The data we obtained in this study proved similar to the studies in the literature that propolis demonstrates a rapid release in water-soluble polymers and the release time increases according to the increasing amount.
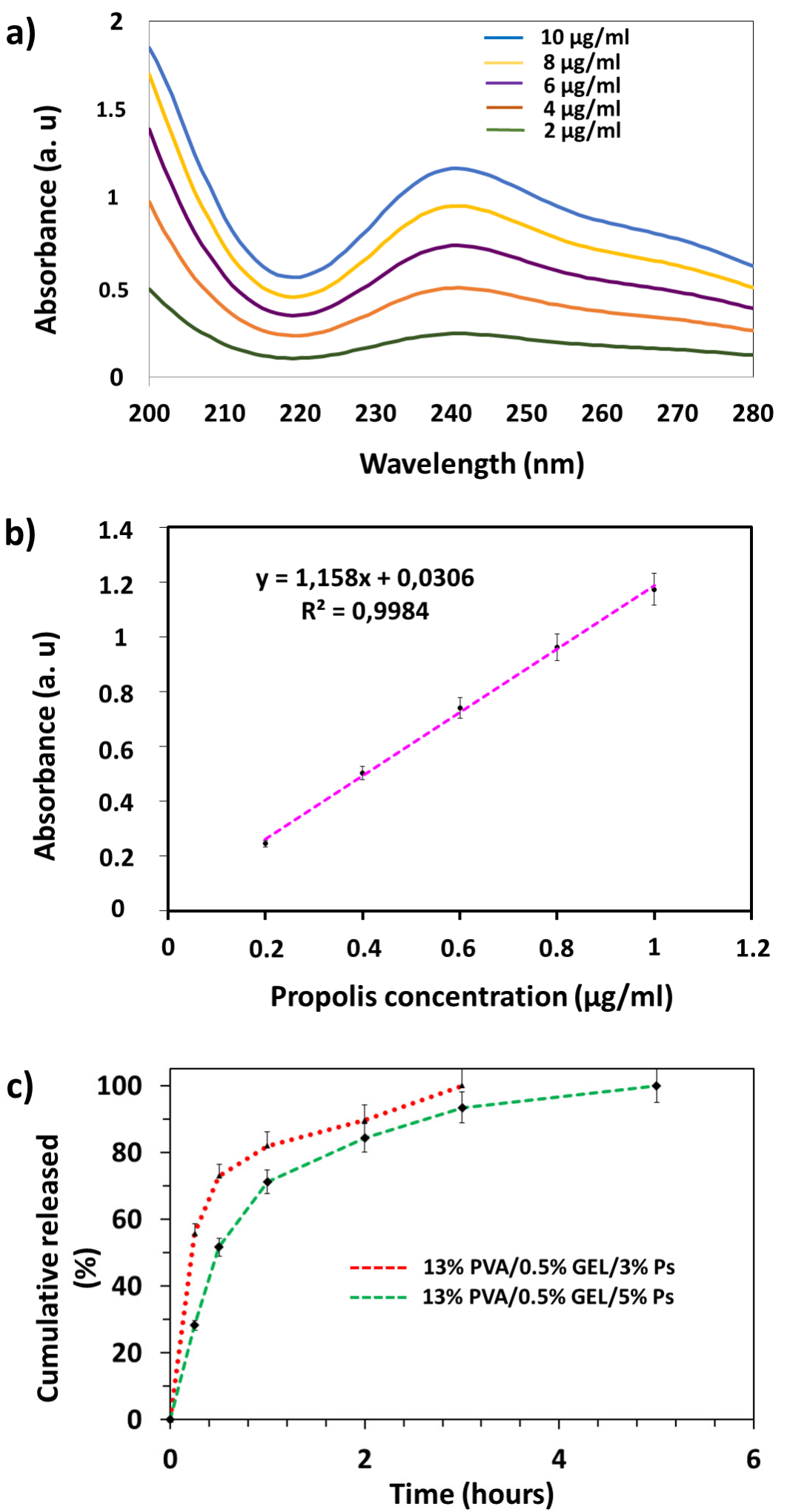

Figure 6. In vitro drug release profiles of scaffolds: Ps calibration curve (a), Absorption spectra of Ps at different amounts (b), Ps cumulative release graph (c). 


\subsection{Biocompatibility Properties of the Corneal Nanofiber Patches}

The MTT assay test, which is a rapid and sensitive technique, is the initial step to evaluate the biological properties of the obtained structures and to examine cell viability and cell proliferation [48]. The cytocompatibility of MSCs on the PVA/GEL and propolis added PVA/GEL patches were shown in Figure 7. According to the cytotoxicity results for the first-day incubation, acceptable viability values of the cells were detected on the $13 \%$ PVA (99\%), 13\% PVA $/ 0.5 \%$ GEL (101\%), 13\% PVA $/ 0.5 \%$ GEL $/ 3 \%$ Ps $(99 \%)$, and $13 \%$ PVA $/ 0.5 \%$ GEL $/ 5 \%$ Ps $(89 \%)$. On the 2 nd day, the viability of the cells on the patches had more than $100 \%$ percentages which demonstrated that cells were proliferated on the patches more than the first day. On the other hand, the viability of the cells decreased on the 7th day of incubation, but they still had acceptable values. Moreover, the viability of the cells on the $13 \%$ PVA still higher than the control group (2D cells). When the samples containing propolis were compared among themselves, it was observed that the cell viability rate in the patch containing 3\% propolis was higher for all incubation times and this can be also correlated with the higher concentration of propolis. This situation can be due to less porous structures and higher diameter values related to the thick fibers [49]. However, we conclude that both $3 \%$ and $5 \%$ propolis added patches are suitable for producing biocompatible corneal patches (to see the biological performance of the patches visually, the fluorescence and SEM images of the MSCs on the patches are reported in the Supplementary Materials Figure S1).

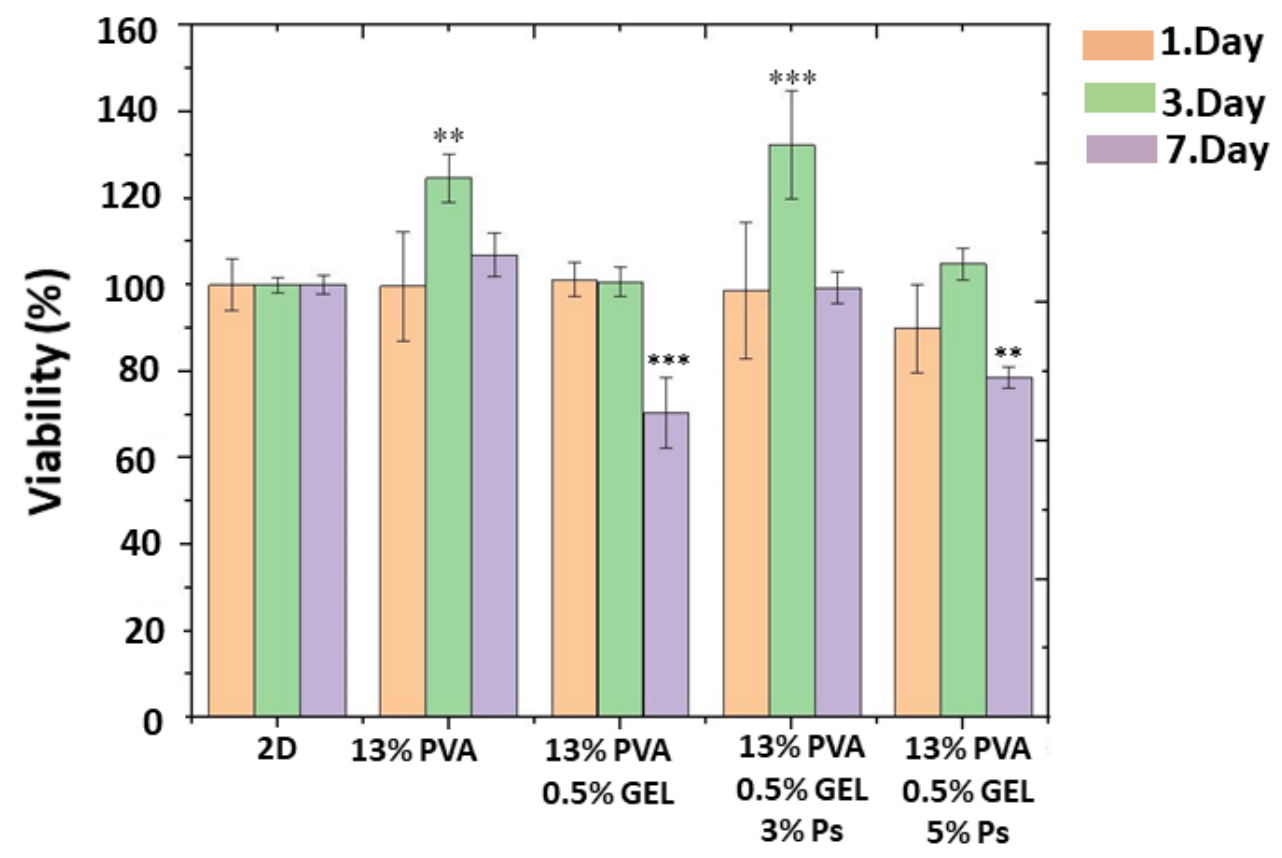

Figure 7. MTT result of the fabricated corneal nanofiber patches and 2D (MSCs) after 1, 3, and 7 days of incubation. The mark "**" points the significant difference $p<0.01$ and the mark “***" represents the significant difference $p<0.001$.

\subsection{Surface Wettability Properties of the Corneal Nanofiber Patches}

The hydrophobic (contact angle $>90$ ) and hydrophilic (contact angle $<90^{\circ}$ ) possessions of the samples have a critical role in the interactions between the extracellular matrix and cells $[50,51]$. Figure 8 showed the surface wettability properties of the corneal nanofiber patches with their contact angles. The contact angle of the $13 \%$ PVA was $38.5^{\circ} \pm 1.7^{\circ}$ approving the hydrophilicity of the patch. The blend 13\% PVA/0.5\% GEL demonstrated lower contact angle $\left(32.6^{\circ} \pm 1.1^{\circ}\right)$ compared to the $13 \%$ PVA. This might be due to multiple surface variations such as phase separation, the hydrophilicity of gel, roughness changes, etc. [52]. By adding 3\% Ps into the $13 \%$ PVA $/ 0.5 \%$ GEL, the contact angle become $26.4^{\circ} \pm 1.5^{\circ}$ indicating that propolis addition decreased the contact angle of the PVA/GEL 
blend. This proved that the surface of the $13 \%$ PVA $/ 0.5 \%$ GEL $/ 3 \%$ Ps patch was the most hydrophilic compared to the other patches indicating that droplets diffused in more on the surface [53]. On the other hand, $5 \%$ Ps ratio increased the contact angle to $42^{\circ} \pm 2.1^{\circ}$, which showed that a higher amount of propolis decreased the hydrophilicity of the $13 \%$ PVA/0.5\% GEL proving the hydrophobic nature of the propolis $[54,55]$.

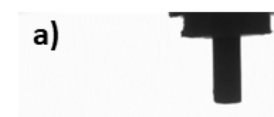

$38.5^{\circ} \pm 1.7^{\circ}$

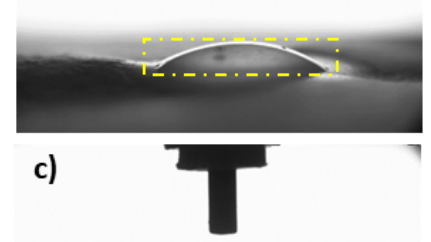

$26.4^{\circ} \pm 1.5^{\circ}$

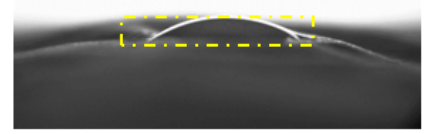

b)

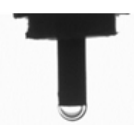

$32.6^{\circ} \pm 1.1^{\circ}$

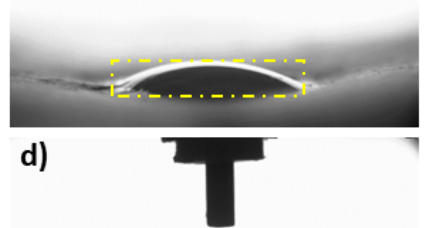

$42^{\circ} \pm 2.1^{\circ}$

Figure 8. Water contact angle properties of the 13\% PVA (a), 13\% PVA/0.5\% GEL (b), 13\% PVA/0.5\% GEL/3\% Ps (c), 13\% PVA/0.5\% GEL/5\% Ps (d).

\section{Conclusions}

In this study, electrospun biocompatible PVA/GEL/Ps nanofiber patches were fabricated to provide the antimicrobial activity against the $S$. aureus and P. aeruginosa, which are the common microorganisms cause the corneal keratitis. The fabricated corneal nanofiber patches were crosslinked with Glutaraldehyde to provide long stability-to avoid the rapid solubilization. Propolis has biocompatibility, and it is a bioactive substance which properties are essential for functional tissue production. According to the SEM results, it can conclude that patches fabricated with electrospinning method are in the nanometer scale, and results demonstrated that the crosslinking process improve the stability (reduce the fast solubilization) and did not alter the morphology of the patches negatively. Antimicrobial test results reported that propolis-based patches showed antibacterial activity against the S. aureus. The $13 \%$ PVA $/ 0.5 \%$ GEL $/ 3 \%$ Ps patch has a high potential due to its proper mechanical properties, notable hydrophilicity, and cell attachment. In the release process, the burst release of propolis was detected in the first hour followed by a sustained release. Based on this study, we reported, for the first time, the functionality and potential of propolis-based patches for the treatment of the corneal keratitis using mesenchymal stem cells, and we demonstrated successful production of corneal patches at a nanometer scale to mimic the structure of the innate cornea tissue.

Supplementary Materials: The following are available online: Figure S1: Fluorescence images of the DAPI stained 13\% PVA (a), 13\% PVA $/ 0.5 \%$ GEL (c), 13\% PVA $/ 0.5 \%$ GEL $/ 3 \%$ Ps (e), $13 \%$ PVA $/ 0.5 \%$ GEL $/ 5 \%$ Ps (g) nanofiber patches, Cell morphology on the $13 \%$ PVA (b), $13 \%$ PVA $/ 0.5 \%$ GEL (d), $13 \%$ PVA $/ 0.5 \%$ GEL $/ 3 \%$ Ps (f), $13 \%$ PVA $/ 0.5 \%$ GEL $/ 5 \%$ Ps (i).

Author Contributions: Conceptualization, S.U., E.I., A.F. and O.G.; Data curation, S.U., E.I., R.D., A.S., B.K.Y., D.F., M.S., B.A. and O.G.; Formal analysis, S.U. and E.I.; Investigation, S.U, E.I. and O.G.; Methodology, S.U., A.M.T., A.F. and O.G.; Supervision, O.G., M.S., A.F. and O.G.; Validation, S.U.; Writing—original draft, S.U., E.I., R.D., A.S., D.F., A.M.T., and O.G.; Writing—review \& editing, S.U., E.I, R.D., B.K.Y., M.S., B.A., D.F., A.F. and O.G. All authors have read and agreed to the published version of the manuscript.

Funding: This research was funded by Marmara University Scientific Research Committee with FDK-2020-10117 project number. The APC was funded by University POLITEHNICA of Bucharest. 
Acknowledgments: The authors thanks to Marmara University Scientific Research Committee (Project Number: FDK-2020-10117) for their financial support.

Conflicts of Interest: The authors declare no conflict of interest.

Sample Availability: Samples of the patches are available from the authors.

\section{References}

1. Fuest, M.; Yam, G.H.F.; Peh, G.S.L.; Mehta, J.S. Advances in corneal cell therapy. Regen. Med. 2016, 11, 601-615. [CrossRef]

2. DelMonte, D.W.; Kim, T. Anatomy and physiology of the cornea. J. Cataract Refract. Surg. 2011, 37, 588-598. [CrossRef]

3. Robaei, D.; Watson, S. Corneal blindness: A global problem. Clin. Exp. Ophthalmol. 2014, 42, 213-214. [CrossRef]

4. Garg, P.; Krishna, P.V.; Stratis, A.K.; Gopinathan, U. The value of corneal transplantation in reducing blindness. Eye 2005, 19, 1106-1114. [CrossRef]

5. Whitcher, J.P.; Sirinivasan, M.; Upadhyay, M.P. Corneal blindness: A global perspective. Bull. World Health Organ. 2001, 79, 214-221.

6. Upadhyay, M.P.; Srinivasan, M.; Whitcher, J.P. Diagnosing and managing microbial keratitis. Community Eye Health J. 2015, 28, 3-6.

7. Stapleton, F.; Carnt, N. Contact lens-related microbial keratitis: How have epidemiology and genetics helped us with pathogenesis and prophylaxis. Eye 2011, 26, 185-193. [CrossRef]

8. Robertson, D.M.; Petroll, W.M.; Jester, J.V.; Cavanagh, H.D. The role of contact lens type, oxygen transmission, and care-related solutions in mediating epithelial homeostasis and Pseudomonas binding to corneal cells: An overview. Eye Contact Lens Sci. Clin. Pr. 2007, 33, 394-398. [CrossRef]

9. Zimmerman, A.B.; Nixon, A.D.; Rueff, E.M. Contact lens associated microbial keratitis: Practical considerations for the optometrist. Clin. Optom. 2016, 8, 1-12. [CrossRef]

10. Astley, R.; Miller, F.C.; Mursalin, M.H.; Coburn, P.S.; Callegan, M.C. An eye on staphylococcus aureus toxins: Roles in ocular damage and inflammation. Toxins 2019, 11, 356. [CrossRef]

11. O'Brien, T.P. Management of bacterial keratitis: Beyond exorcism towards consideration of organism and host factors. Eye 2003, 17, 957-974. [CrossRef]

12. Cesur, S.; Oktar, F.N.; Ekren, N.; Kilic, O.; Alkaya, D.B.; Seyhan, S.A.; Ege, Z.R.; Lin, C.-C.; Kuruca, S.E.; Erdemir, G.; et al. Preparation and characterization of electrospun polylactic acid/sodium alginate/orange oyster shell composite nanofiber for biomedical application. J. Aust. Ceram. Soc. 2019, 56, 533-543. [CrossRef]

13. Li, W.-J.; Laurencin, C.T.; Caterson, E.J.; Tuan, R.S.; Ko, F.K. Electrospun nanofibrous structure: A novel scaffold for tissue engineering. J. Biomed. Mater. Res. 2002, 60, 613-621. [CrossRef] [PubMed]

14. Bhattarai, S.R.; Bhattarai, N.; Yi, H.K.; Hwang, P.H.; Cha, D.I.; Kim, H.Y. Novel biodegradable electrospun membrane: Scaffold for tissue engineering. Biomaterials 2004, 25, 2595-2602. [CrossRef]

15. Heydarkhan-Hagvall, S.; Schenke-Layland, K.; Dhanasopon, A.P.; Rofail, F.; Smith, H.; Wu, B.M.; Shemin, R.; Beygui, R.E.; MacLellan, W.R. Three-dimensional electrospun ECM-based hybrid scaffolds for cardiovascular tissue engineering. Biomaterials 2008, 29, 2907-2914. [CrossRef] [PubMed]

16. Cesur, S.; Ulag, S.; Ozak, L.; Gumussoy, A.; Arslan, S.; Yilmaz, B.K.; Ekren, N.; Agirbasli, M.; Kalaskar, D.M.; Gunduz, O. Production and characterization of elastomeric cardiac tissue-like patches for Myocardial Tissue Engineering. Polym. Test. 2020, 90, 106613. [CrossRef]

17. Ilhan, E.; Cesur, S.; Guler, E.; Topal, F.; Albayrak, D.; Guncu, M.M.; Cam, M.E.; Taskin, T.; Sasmazel, H.T.; Aksu, B.; et al. Development of Satureja cuneifolia-loaded sodium alginate/polyethylene glycol scaffolds produced by 3D-printing technology as a diabetic wound dressing material. Int. J. Biol. Macromol. 2020, 161, 1040-1054. [CrossRef]

18. Yusong, P.; Jie, D.; Yan, C.; Qianqian, S. Study on mechanical and optical properties of poly(vinyl alcohol) hydrogel used as soft contact lens. Mater. Technol. 2016, 31. [CrossRef]

19. Ulag, S.; Ilhan, E.; Aksu, B.; Sengor, M.; Ekren, N.; Kilic, O.; Gunduz, O. Patch-Based Technology for Corneal Microbial Keratitis. In Proceedings of the Lecture Notes in Computer Science (Including Subseries Lecture Notes in Artificial Intelligence and Lecture Notes in Bioinformatics); Springer: Cham, Switzerland, 2020; Volume 12108, pp. 194-200.

20. Cesur, S.; Cam, M.E.; Sayın, F.S.; Su, S.; Gunduz, O. Controlled Release of Metformin Loaded Polyvinyl Alcohol (PVA) Microbubble/Nanoparticles Using Microfluidic Device for the Treatment of Type 2 Diabetes Mellitus. In Proceedings of the Lecture Notes in Computer Science (Including Subseries Lecture Notes in Artificial Intelligence and Lecture Notes in Bioinformatics); Springer: Cham, Switzerland, 2020; Volume 12108, pp. 185-193.

21. Mad-Ali, S.; Benjakul, S.; Prodpran, T.; Maqsood, S. Characteristics and gelling properties of gelatin from goat skin as affected by drying methods. J. Food Sci. Technol. 2017, 54, 1646-1654. [CrossRef]

22. Pal, K.; Banthia, A.K.; Majumdar, D.K. Preparation and characterization of polyvinyl alcohol-gelatin hydrogel membranes for biomedical applications. AAPS PharmSciTech 2007, 8, E142-E146. [CrossRef]

23. Huang, C.Y.; Hu, K.H.; Wei, Z.H. Comparison of cell behavior on pva/pva-gelatin electrospun nanofibers with random and aligned configuration. Sci. Rep. 2016, 6, 37960. [CrossRef] 
24. Jain, D.; Carvalho, E.; Banthia, A.K.; Banerjee, R. Development of polyvinyl alcohol-gelatin membranes for antibiotic delivery in the eye. Drug Dev. Ind. Pharm. 2011, 37, 167-177. [CrossRef]

25. Oliveira, R.N.; McGuinness, G.B.; Rouze, R.; Quilty, B.; Cahill, P.; Soares, G.D.A.; Thiré, R.M.S.M. PVA hydrogels loaded with a Brazilian propolis for burn wound healing applications. J. Appl. Polym. Sci. 2015, 132, 132. [CrossRef]

26. Albayrak, S.; Albayrak, S. Propolis: Natural antimicrobial matter. Ankara Univ. Eczac. Fak. Derg. 2008, 37, 201-215. [CrossRef]

27. Fernández, M.C.; Cuesta-Rubio, O.; Perez, A.R.; De Oca Porto, R.M.; Hernández, I.M.; Piccinelli, A.L.; Rastrelli, L. GC-MS determination of isoflavonoids in seven red cuban propolis samples. J. Agric. Food Chem. 2008, 56, 9927-9932. [CrossRef]

28. Cui-ping, Z.; Shuai, H.; Wen-ting, W.; Shun, P.; Xiao-ge, S.; Ya-jing, L.; Fu-liang, H. Development of High-Performance Liquid Chromatographic for Quality and Authenticity Control of Chinese Propolis. J. Food Sci. 2014, 79, C1315-C1322. [CrossRef] [PubMed]

29. Huang, S.; Zhang, C.P.; Wang, K.; Li, G.Q.; Hu, F.L. Recent advances in the chemical composition of propolis. Molecules 2014, 19, 19610-19632. [CrossRef] [PubMed]

30. Marcucci, M.C. Propolis: Chemical composition, biological properties and therapeutic activity. Apidologie 1995, 26, 83-99. [CrossRef]

31. Cumbao, J.L.T.; Alvarez, P.L.J.; Belina-Aldemita, M.D.; Micor, J.R.L.; Angelia, M.R.N.; Manila-Fajardo, A.C.; Cervancia, C.R. Total phenolics, total flavonoids, antioxidant activity and antibacterial property of propolis produced by the stingless bee, Tetragonula biroi (Friese), from Laguna and Quezon, Philippines. Philipp. Entomol. 2016, 30, 63-74.

32. Meimandi-Parizi, A.; Oryan, A.; Sayahi, E.; Bigham-Sadegh, A. Propolis extract a new reinforcement material in improving bone healing: An in vivo study. Int. J. Surg. 2018, 56, 94-101. [CrossRef]

33. Ahlawat, J.; Kumar, V.; Gopinath, P. Carica papaya loaded poly (vinyl alcohol)-gelatin nanofibrous scaffold for potential application in wound dressing. Mater. Sci. Eng. C 2019, 103, 109834. [CrossRef]

34. Sharaf, S.; El-Naggar, M.E. Wound dressing properties of cationized cotton fabric treated with carrageenan/cyclodextrin hydrogel loaded with honey bee propolis extract. Int. J. Biol. Macromol. 2019, 133, 583-591. [CrossRef]

35. Derkach, S.R.; Voron'ko, N.G.; Sokolan, N.I.; Kolotova, D.S.; Kuchina, Y.A. Interactions between gelatin and sodium alginate: UV and FTIR studies. J. Dispers. Sci. Technol. 2020, 41, 690-698. [CrossRef]

36. Linh, N.T.B.; Lee, B.T. Electrospinning of polyvinyl alcohol/gelatin nanofiber composites and cross-linking for bone tissue engineering application. J. Biomater. Appl. 2012, 27, 255-266. [CrossRef]

37. Ang, L.F.; Darwis, Y.; Por, L.Y.; Yam, M.F. Microencapsulation curcuminoids for effective delivery in pharmaceutical application. Pharmaceutics 2019, 11, 451. [CrossRef]

38. Bonilla, J.; Bittante, A.M.Q.B.; Sobral, P.J.A. Thermal analysis of gelatin-chitosan edible film mixed with plant ethanolic extracts. J. Therm. Anal. Calorim. 2017, 130, 1221-1227. [CrossRef]

39. Do Nascimento, T.G.; da Silva, P.F.; Azevedo, L.F.; da Rocha, L.G.; de Moraes Porto, I.C.C.; Lima e Moura, T.F.A.; Basílio-Júnior, I.D.; Grillo, L.A.M.; Dornelas, C.B.; da Fonseca, S.E.J.; et al. Polymeric Nanoparticles of Brazilian Red Propolis Extract: Preparation, Characterization, Antioxidant and Leishmanicidal Activity. Nanoscale Res. Lett. 2016, 11, 1-16. [CrossRef] [PubMed]

40. Gupta, S.; Pramanik, A.K.; Kailath, A.; Mishra, T.; Guha, A.; Nayar, S.; Sinha, A. Composition dependent structural modulations in transparent poly(vinyl alcohol) hydrogels. Colloids Surfaces B Biointerfaces 2009, 74, 186-190. [CrossRef] [PubMed]

41. Archondouli, P.S.; Kallitsis, J.K.; Kalfoglou, N.K. Compatibilization and property characterization of polycarbonate/polyurethane polymeric alloys. J. Appl. Polym. Sci. 2003, 89, 287. [CrossRef]

42. Sadeghi, A.; Pezeshki-Modaress, M.; Zandi, M. Electrospun polyvinyl alcohol/gelatin/chondroitin sulfate nanofibrous scaffold: Fabrication and in vitro evaluation. Int. J. Biol. Macromol. 2018, 114, 1248-1256. [CrossRef]

43. Arıan, H.K.; Solak, H.H. Propolis Extract-PVA Nanocomposites of Textile Design: Antimicrobial Effect on Gram Positive and Negative Bacterias. Int. J. Second. Metab. 2017, 4, 218-224. [CrossRef]

44. Silici, S.; Kutluca, S. Chemical composition and antibacterial activity of propolis collected by three different races of honeybees in the same region. J. Ethnopharmacol. 2005, 99, 69-73. [CrossRef]

45. Aranci, K.; Uzun, M.; Su, S.; Cesur, S.; Ulag, S.; Amin, A.; Guncu, M.M.; Aksu, B.; Kolayli, S.; Ustundag, C.B.; et al. 3D Propolis-Sodium Alginate Scaffolds: Influence on Structural Parameters, Release Mechanisms, Cell Cytotoxicity and Antibacterial Activity. Molecules 2020, 25, 5082. [CrossRef] [PubMed]

46. Kim, J.I.; Pant, H.R.; Sim, H.J.; Lee, K.M.; Kim, C.S. Electrospun propolis/polyurethane composite nanofibers for biomedical applications. Mater. Sci. Eng. C 2014, 44, 52-57. [CrossRef]

47. Ulag, S.; Ilhan, E.; Sahin, A.; Karademir Yilmaz, B.; Kalaskar, D.M.; Ekren, N.; Kilic, O.; Nuzhet Oktar, F.; Gunduz, O. 3D printed artificial cornea for corneal stromal transplantation. Eur. Polym. J. 2020, 133, 109744. [CrossRef]

48. Ilhan, E.; Ulag, S.; Sahin, A.; Yilmaz, B.K.; Ekren, N.; Kilic, O.; Sengor, M.; Kalaskar, D.M.; Oktar, F.N.; Gunduz, O. Fabrication of tissue-engineered tympanic membrane patches using 3D-Printing technology. J. Mech. Behav. Biomed. Mater. 2021, $114,104219$. [CrossRef] [PubMed]

49. Mishima, S.; Narita, Y.; Chikamatsu, S.; Inoh, Y.; Ohta, S.; Yoshida, C.; Araki, Y.; Akao, Y.; Suzuki, K.M.; Nozawa, Y. Effects of propolis on cell growth and gene expression in HL-60 cells. J. Ethnopharmacol. 2005, 99, 5-11. [CrossRef]

50. Unal, S.; Arslan, S.; Karademir Yilmaz, B.; Kazan, D.; Oktar, F.N.; Gunduz, O. Glioblastoma cell adhesion properties through bacterial cellulose nanocrystals in polycaprolactone/gelatin electrospun nanofibers. Carbohydr. Polym. 2020, 233, 115820. [CrossRef] [PubMed] 
51. Wu, G.; Yang, Y.; Lei, Y.; Fu, D.; Li, Y.; Zhan, Y.; Zhen, J.; Teng, M. Hydrophilic nano-SiO2/PVA-based coating with durable antifogging properties. J. Coat. Technol. Res. 2020, 17, 1145-1155. [CrossRef]

52. Ino, J.M.; Sju, E.; Ollivier, V.; Yim, E.K.F.; Letourneur, D.; Le Visage, C. Evaluation of hemocompatibility and endothelialization of hybrid poly(vinyl alcohol) (PVA)/gelatin polymer films. J. Biomed. Mater. Res. Part B Appl. Biomater. 2013, 101, 1549-1559. [CrossRef]

53. Jiang, H.; Zuo, Y.; Zhang, L.; Li, J.; Zhang, A.; Li, Y.; Yang, X. Property-based design: Optimization and characterization of polyvinyl alcohol (PVA) hydrogel and PVA-matrix composite for artificial cornea. J. Mater. Sci. Mater. Med. 2014, 25, 941-952. [CrossRef] [PubMed]

54. Kim, J.; Shin, D.H.; Lee, W.J. Suicidal ideation and occupational pesticide exposure among male farmers. Environ. Res. 2014, 128, 52-56. [CrossRef] [PubMed]

55. Bilginer, R.; Arslan Yildiz, A. A facile method to fabricate propolis enriched biomimetic PVA architectures by co-electrospinning. Mater. Lett. 2020, 276, 128191. [CrossRef] 